\title{
PARA UM NOVO PARADIGMA DE ESTADO PLURINACIONAL NA AMÉRICA LATINA
}

FOR A NEW PARADIGM OF PLURINATIONAL STATE IN LATIN AMERICA

PARA UN NUEVO PARADIGMA DE ESTADO PLURINACIONAL EN AMÉRICA LATINA

Antonio Carlos Wolkmer ${ }^{1}$

Lucas Machado Fagundes ${ }^{2}$

RESUMO

Trata-se de uma reflexão teórica sobre a formação histórica do Estado na América Latina, oportunizando um repensar crítico-construtivo dos aspectos jurídico e político atuais, proporcionado pela entrada em cena de sujeitos ausentes da história oficial. Objetiva-se apresentar a emergência de novas práticas políticas que vêm alterando os horizontes jurídicos (Direito Público), exigindo discussões teórico-práticas imediatas sobre o campo institucional. Conformam-se as principais disposições do novo momento no pensamento político-jurídico, inserido no percurso de ruptura aos padrões do constitucionalismo de base europeia/ colonizadora. Busca-se, assim, resgatar as relações entre constituição, sujeitos negados, pluralismo e interculturalidade, na convergência de forças políticas diversificadas em dado momento histórico e espaço geopolítico contemporâneo, tendo em conta, fundamentalmente, a proposta de refundação do Estado (Estado Plurinacional), extraída dos novos textos constitucionais latino-americanos.

PALAVRAS-ChAVE: Política. Direito. Refundação do Estado. Novo Constitucionalismo. América Latina.

\section{ABSTRACT}

This work is a theoretical reflection on the historical formation of the state in Latin America, promoting a critical and constructive rethinking of aspects of the current legal and political environment provided by the entrance of subjects that were absent from the official history. It presents the emergence of new political practices that have been changing the legal landscape (Public Law), and that call for immediate theoretical and practical discussions on the institutional field. The main provisions of the new period in political and legal thinking are outlined, inserted in a process of breaking away from the patterns of European/colonizing constitutionalism. Thus, this work seeks to revive relationships between constitutions, denied subjects, pluralism and interculturality, in the convergence of diversified political forces at a particular historical time and contemporary geopolitical space, taking into account, fundamentally, the proposed overhaul of the Plurinational State, extracted from the new Latin American constitutions.

KEYWORDS: Politics. Law. Overhaul of the State. New Constitutionalism. Latin America.

1 Professor Titular de História das Instituições Jurídicas, dos cursos de graduação e pós-graduação em Direito da UFSC, Florianópolis-SC-Brasil. Doutor em Direito e membro do Instituto dos Advogados Brasileiros (RJ). É pesquisador nível 1 do CNPq. Professor visitante de cursos de pós-graduação em várias universidades do Brasil e do exterior (Argentina, Peru, Colômbia, Chile,Venezuela, Costa Rica, México, Espanha e Itália). wolkmer@yahoo.com.br

2 Doutorando em Direito - Universidade Federal de Santa Catarina - UFSC, Florianópolis-SC-Brasil. Mestre em Direito - Filosofia, Teoria e História do Direito - pelo Programa de Pós-graduação em Direito - UFSC, Membro do NEPE - Núcleo de Estudo e Práticas Emancipatórias. Pesquisador bolsista CNPq - Brasil. lucas-sul@hotmail.com 
Se trata de una reflexión teórica sobre la formación histórica del Estado en América Latina, oportunizando una reflexión crítico constructiva acerca de los aspectos jurídicos y políticos actuales, proporcionados por la entrada en escena de sujetos ausentes de la historia oficial. El objetivo es presentar la emergencia de nuevas prácticas políticas que vienen alterando los horizontes jurídicos (Derecho Público), exigiendo discusiones teórico prácticas inmediatas sobre el campo institucional. Se delinean las principales disposiciones del nuevo momento en el pensamiento político jurídico, surgido durante la ruptura de los modelos del constitucionalismo de base europea colonizadora. Se busca, así, rescatar las relaciones entre constitución, sujetos negados, pluralismo e interculturalidad, en la convergencia de fuerzas políticas diversificadas en determinado momento histórico y espacio geopolítico contemporáneo, tomando en cuenta, fundamentalmente, la propuesta de refundación del Estado (Estado Plurinacional), extraída de los nuevos textos constitucionales latinoamericanos.

PALABRAS ClAVE: Política. Derecho. Refundación del Estado. Nuevo Constitucionalismo. América Latina.

\section{INTRODUÇÃO}

Importa entender a tradição da cultura política e jurídica na América Latina como reflexo das diferenças estruturais e das contradições sociais em seus diversos momentos históricos de avanços e recuos.

A dinâmica de contextualização latino-americana tem sido marcada por um cenário construído pela dominação interna e pela submissão externa. Trata-se de uma trajetória fundada na lógica da colonização, da exploração e da exclusão dos múltiplos segmentos étnicos, religiosos e societários. Um horizonte de contradições e desequilíbrios sociais, dominado pelo autoritarismo e pela violência de minorias detentoras do poder e pela marginalidade e resistência das maiorias "ausentes da história"', como os movimentos indígenas, negros, campesinos e massas populares.

A adesão de modelos culturais incorporadas pelas elites locais (matrizes eurocêntrica e norte-americana) tem proporcionado estruturas de dominação econômica e de exclusão social, impossibilitando a evolução para uma cultura política e jurídica verdadeiramente latino-americana de matriz pluricultural e compartilhada.

Eis, portanto, os intentos da presente incursão que, além de examinar os processos históricos do Estado periférico e da implantação dos parâmetros eurocêntricos aos países da América Latina, prioriza, igualmente, o reconhecimento dos novos movimentos político-jurídicos nos países andinos e suas mudanças paradigmáticas na esfera do Estado (Estado Plurinacional) e do Direito (Pluralismo Jurídico). Decorre, por conseguinte, um panorama introdutório de inovações que se apresentam no espaço geopolítico de lutas sócio-político-históricas, avançando para o novo Constitucionalismo pluralista intercultural, discussão contemporânea que vem contribuir, institucionalmente, para a refundação do Estado na América Latina.

\section{PARÂMETROS SOCIOPOLÍTICOS DO ESTADO DEPENDENTE LATINO-AMERICANO}

Contrariamente à construção do modelo estatal na Europa, legitimado por uma classe média liberal individualista, que transpõe o aparato aristocrático-feudal, a experiência de formação do Estado nas Sociedades periférico-dependentes da América Latina adquire algumas particularidades distintas. Antes de tudo, há que se assinalar que o Estado não é produto de uma sociedade nacional e politicamente ordenada, muito menos da criação exclusiva de um segmento economicamente

3 Gutierrez, Gustavo. A Força Histórica dos Pobres. 2. ed. Petrópolis: Vozes, 1984. 
hegemônico, tampouco da sociodiversidade existente no continente, mas sim do próprio Estado como construtor que irá ter a função privilegiada em assegurar a estratificação dos segmentos sociais e em modelar as sociedades nacionais existentes. Assim, diante do perfil essencialmente frágil das elites nacionais, subordinadas aos intentos de acumulação produtiva das metrópoles, surge um modelo estatal que se legitima para encaminhar a sociedade civil, para efetivar as transformações estruturais independente da presença dos setores autóctones ou faç̧ões culturais regionais, para validar o espaço público na intermediação entre as oligarquias rurais e as burguesias estrangeiras, garantindo o consenso dos subordinados por meio de uma política de cooptação e de distribuição clientelística de favores. Naturalmente, o aparecimento do Estado-Nação na América Latina se efetiva, no início do século XIX, diante das condições histórico-políticas contraditórias e do surto dos movimentos nacionalistas de independência contra os colonizadores luso-hispânicos.

Certamente que a grande contradição que fica desenhada no período pós-independência é a da montagem de um Estado liberal republicano (com exceção do Império brasileiro) idealizado, mas que vai se consolidando em um cenário dominado por práticas oligárquicas e por formas de dominação conservadoras.

Assim, o Estado, na América Latina, abrange, por conseguinte, uma estrutura de múltiplos aspectos e que, por sua complexidade, torna-se difícil fixar um único paradigma, o que tem levado a diversas interpretações de um fenômeno estudado classicamente como Estado Oligárquico (Torcuato Di Tella, Gino Germani, Octavio Ianni, Francisco Weffort), Estado de Capitalismo Dependente (Fernando H. Cardoso, Enzo Faletto, Anibal Quijano etc. ), Estado do Subdesenvolvimento Capitalista (Theotônio dos Santos, Rui M. Marini, André Gunder Frank etc.), Estado Pretoriano ou Militar (Samuel Huntington, Alain Rousquié), Estado Patrimonialista ou Burocrático-estamental (Raymundo Faoro, Simon Schwartzman), Estado Autoritário-Burocrático (Guillermo O'Donnell, David Collier etc.), Estado Corporativo (Alfred Stepan, Howard J. Wiarda, Philippe C. Schmitter), Estado Plurinacional (Alberto Acosta, Alvaro Garcia Linera, Catherine Walsh), etc.

Mesmo que se venha distinguir uma noção de Estado periférico latino-americano, a partir de determinados eixos históricos similares e comuns, não se pode deixar de ter presente a "especificidade" da dinâmica de constituição dos diferentes "modelos estatais" e a necessária relação com os desdobramentos do Estado nacional de tradição liberal-individualista. De qualquer modo, cabe questionar as versões que projetam o Estado latino-americano, ora como órgão abstrato, homogeneizador e árbitro equidistante dos antagonismos sociais, ora como fenômeno produzido pelo jogo determinista de uma estrutura econômica, instrumentalizando a dominação de um segmento societário ou uma classe sobre outra ${ }^{4}$. Sem cair no reducionismo clássico dos modelos liberal, coletivismo estatista ou corporativismo autoritário, a reconstrução implicará a necessidade de se reordenar, criticamente, um novo conceito de Estado (sob o viés da plurinacionalidade), adequado às particularidades socioeconômicas e político-culturais da América Latina. Esse fator estará evidenciado nos próximos parágrafos quando for retomada a ideia de (re)fundar o Estado na América Latina.

$\mathrm{Na}$ análise histórica do Estado periférico latino-americano, dentre os diversos processos de formação, um modelo que cabe destacar acerca de sua especificidade política foi o que se constituiu no Brasil, bem como quais foram os atores e os interesses que contribuíram para normatizar a organização interna das relações de produção e das condições sociais promovidas, após a independência, no início do século XIX. Comparativamente, a formação do Estado moderno europeu edificou-se como resultado do desenvolvimento secular da sociedade, da formalização racional do poder político e da identidade de uma nação consolidada, bem como da ascensão de uma camada social burguesa individualista inserida na prática política parlamentar representativa e no jogo do livre mercado econômico. Tratava-se de uma instância política burocrática, centralizada e racionalizada, embasada nos princípios da liberdade, divisão dos poderes e da propriedade privada. Já os países colonizados da periferia latino-americana, submetidos a um capitalismo tardio e sem possuírem uma sociedade de classe média coesa e sem reconhecer as autonomias culturais nativas, vivenciaram uma modernização de tipo conservadora, instaurada pelo próprio Estado, que se fez representar por oligarquias brancas e escravocratas, provindas geralmente de regiões economicamente dominantes de seus países e embuídos de ideários culturais eurocêntricos.

4 MARTNER, Gonzalo (Coord.). "El Estado en América Latina". América Latina hacia el 2000. Caracas: Editorial Nueva Sociedad/UNITAR, 1986, p. 142-153. 
Tal processo explicita o caso brasileiro, pois, sem que existisse uma sociedade institucionalmente organizada em torno de uma identidade nacional, impôs-se, formalmente, um Estado "independente" e "soberano", criado distintamente dos interesses da população que integrava a sociedade, no período que se inaugurou entre a transferência do Estado Imperial português para o Brasil e a independência do país, em $1822^{5}$. Como decorrência, o próprio Estado imperial incentivou, de pronto, a profissionalização de setores sociais burocráticos para as tarefas da administração e do governo. Tais segmentos burocráticos, treinados nas tradições do mercantilismo, do patrimonialismo e do absolutismo português, eram recrutados socialmente, no dizer de José Murilo de Carvalho, de setores vinculados à mineração, ao comércio e à propriedade da terra ${ }^{6}$. Assim, desde suas origens e prosseguindo em toda história brasileira, as "elites" oligárquicas e latifundiárias tiveram um papel de relevo no exercício hegemônico de controle do aparato estatal e no exercício da dominação política, sempre muito subservientes aos interesses do capitalismo mundial e alheias totalmente aos intentos da população e de suas diferenças étnicas. Os traços desta supremacia de poder dos extratos oligárquicos edificará, no Império, a burocracia dos magistrados e dos bacharéis de Direito e, na República, a burocracia dos tecnocratas civis em alianças com as corporações militares.

Revela-se, assim, em seu processo constitutivo, que o Estado brasileiro, além de incorporar a montagem patrimonialista e centralizadora do sistema de administração lusitana, surge sem uma identidade nacional, completamente desvinculado dos objetivos de sua população de origem e da pluralidade cultural existente no corpo de sua sociedade. Equidistantes dos intentos mais autênticos das coletividades nativas e locais, a potência luso-colonizadora transfere o poder real para a Colônia, assentando uma estrutura de poder monárquica que se serve de uma burocracia estamental, originada dos senhores de escravos e proprietários de terras. A composição entre o poder aristocrático da coroa com as elites agrárias locais permite, historicamente, no período mesmo que sucede a Independência, consolidar o projeto nacional de segmentos sociais possuidores da propriedade, do capital e do monopólio do mercado. Ainda que com o advento das rupturas políticas e econômicas do país (Independência, Proclamação da República, Revolução de 30, etc.), e com os deslocamentos dos estratos sociais hegemônicos, imperiais e republicanos, o Estado periférico, incorporando o paradigma de Estado-Nação, age como uma "instância" abstrata e contraditória, assumindo diante da desigual, inerte e fragmentada sociedade a responsabilidade pela unidade institucional necessária para compor a identidade nacional e para implementar, no transcurso republicano, o desenvolvimento capitalista-industrial. Em determinadas etapas da evolução nacional (período pós30), diante da imobilidade dos setores burgueses dissidentes, da grande parcela de coletividades excluídas e de um corpo político fragmentado pelos poderes regionais, o Estado nacional periférico acaba se projetando para ocupar o vazio existente, como um "sujeito político"7 unilateral que se legitima, por meio da coerção, para unificar, nacionalmente, a sociedade oligárquica, marcada por descriminações e exclusões de sociabilidades culturalmente diferenciadas.

Ademais, ao se discutir a formação e a evolução do paradigma de Estado periférico latinoamericano, realçando a especificidade da experiência brasileira, não menos significativo, por sua composição e por suas relações, é trazer a contextualização ao cenário regional das práticas políticas e normativas instituídas nesta tradição monista e eurocêntrica. Assim, ampliam-se e se estendem tais processos sedimentadores aos demais países latino-americanos, ressaltando a ausência histórica das massas populares excluídas do poder, como as nações indígenas, os afrodescendentes e os camponeses, não incorporados ao movimento de construção formal do Estado-Nação, projetando uma prática institucional de cultura nacional "encoberta" e marginalizada, sufocando as possibilidades de reconhecimento de um Estado de representação pluricultural.

\section{(RE)CONTEXTUALIZANDO O ESTADO E O DIREITO LATINO- AMERICANO A PARTIR DOS SUJEITOS PRODUZIDOS COMO AUSENTES}

Tendo em vista o que foi desenvolvido no item anterior, urge destacar a necessidade de repensar o Estado e o Direito a partir da geografia latino-americana. As lógicas político-jurídicas acima

5 PIRES, Cecília M. Pinto. Reflexões sobre Filosofia Política. Santa Maria: Pallotti, 1986, p. 47-48.

6 CARVALHO, José Murilo de. A Construção da Ordem: a elite política imperial. Rio de Janeiro: Campus, 1980, p. 178.

7 PIRES, Cecília M. Pinto. Reflexões sobre Filosofia Política. Santa Maria: Pallotti, 1986, p. 51. 
ignoraram as amplas maiorias populares existentes no contexto local, e é justamente sobre estes sujeitos políticos ausentes que irá centrar-se esta etapa do presente estudo.

Contudo, antes de se adentrar no desenvolvimento temático, devem-se abordar algumas questões delimitativas de relevância contextual, ou seja, situar uma linha temporal que marca a atualidade dos sujeitos recentes envolvidos na história latino-americana, isso se torna importante para delinear quem são estes personagens genericamente mencionados na primeira parte. Assim, localiza-se geopoliticamente o espaço-tempo da busca por uma mudança paradigmática, de um processo iniciado ao ano de 1492, com a invasão da América pelos europeus (em crise) na busca de novas rotas para solucionar seus problemas de ordem socioeconômico.

Tal processo denominado "modernidade" é um fenômeno "gestado"8 no velho continente europeu ao início da afirmação dos Estados unitários e que culmina com a invasão, a conquista e a colonização da América indiana. Neste aspecto, faz-se referência, na presente discussão, a obra 1492 - O encobrimento do Outro: a origem do mito da modernidade, autoria de Enrique Dussel, que desmitifica a história, via de regra, ensinada; desmonta as falácias em torno da formação do povo latino-americano; e configura-se como uma das principais contribuições para a reinvenção de outra América Latina, voltada à libertação do modelo colonizador eurocêntrico.

Para Dussel ${ }^{9}$, o nascimento da modernidade surge no ano de 1492,

(...) data do "nascimento" da Modernidade; embora sua gestação - como o feto - leve um tempo de crescimento intra-uterino. A modernidade originou-se nas cidades europeias medievais, livres, centros de enorme criatividade. Mas "nasceu" quando a Europa pôde se confrontar como o seu "Outro" e controlá-lo, vencê-lo, violentá-lo: quando pôde se definir como um "ego" descobridor, conquistador, colonizador da Alteridade constitutiva da própria Modernidade. De qualquer maneira, esse Outro não foi "descoberto" como Outro, mas foi "en-coberto" como o "si-mesmo" que a Europa já era desde sempre. De maneira que 1492 será o momento do nascimento da Modernidade como conceito, o momento concreto da "origem" de um "mito" de violência sacrificial muito particular, e, ao mesmo tempo, um processo de "en-cobrimento" do não-europeu. ${ }^{10}$

Esse processo é peculiar não somente nas suas facetas econômico, político e social as quais representa, mas também no alto grau de influência epistemológica e de (de)formação dos arquétipos culturais dos povos latino-americanos. Igualmente, José Carlos Moreira da Silva Filho traduz o significado do processo de criação da modernidade desde um ponto de vista ontológico,

\begin{abstract}
Trata-se de uma posição ontológica pela qual se pensa que o desenvolvimento empreendido pela Europa deverá ser unilinearmente seguido. É uma categoria filosófica fundamental e não só sociológica ou econômica. "É o movimento necessário do Ser, para Hegel, seu desenvolvimento inevitável". (...) Assim, a Europa cristã moderna tem um princípio em si mesma, e é sua plena realização. E mais, somente parte ocidental norte da Europa é considerada por Hegel como o núcleo da história: "A Alemanha, França, Dinamarca, os países escandinavos são o coração da Europa". Logo, Espanha e Portugal, e consequentemente a América Latina e sua "descoberta", não possuem a menor importância na constituição da modernidade; isto, observa Dussel, é verificável tanto em Hegel quanto, contemporaneamente, em Habermas. ${ }^{11}$
\end{abstract}

Com esta visão filosófica de mundo, o "sujeito europeu" chegou de forma alienígena ao modo de vida e aos costumes do nativo que habitava o continente, chamado equivocadamente de Índias e que posteriormente veio ser denominada América Latina.

$\mathrm{Na}$ invenção da modernidade, utilizaram-se eficientes mecanismos de fundamentação, que sempre se justificaram pelo eurocentrismo, o mito desenvolvimentista e a aculturação do índio americano. A própria forma de ver os povos não europeus legitimou a dominação, via de regra violenta, responsável por algumas das maiores hecatombes da história da humanidade: a escravidão indígena e negra ${ }^{12}$.

8 DUSSEL, Enrique. 1492: o encobrimento do outro: a origem do mito da modernidade, conferências de Frankfurt. Tradução de Jaime A. Classen. Petrópolis: Vozes, 1993.

9 DUSSEL, Enrique. 1492: o encobrimento do outro: a origem do mito da modernidade, conferências de Frankfurt. Tradução de Jaime A. Classen. Petrópolis: Vozes, 1993.

10 DUSSEL, Enrique. 1492: o encobrimento do outro: a origem do mito da modernidade, conferências de Frankfurt. Tradução de Jaime A. Classen. Petrópolis: Vozes, 1993, p. 8.

11 SILVA FILHO, José Carlos Moreira da. In: WOLKMER, Antonio Carlos. (Org.) Fundamentos de História do Direito. 4. ed. Rev. e Atual. Belo Horizonte: Del Rey, 2009, p. 274

12 DUSSEL, Enrique. 1492: o encobrimento do outro: a origem do mito da modernidade, conferências 
Afirmada esta realidade, vale ressaltar que a colonização não se extinguiu com a independência formal do Estado-Nação, que fora assimilado à cultura da metrópole. A independência real de vida e da cultural, atualmente, expressa em um movimento que ainda está sendo moldado pelos povos do continente latino-americano, é uma dinâmica que tem seus reflexos hodiernamente no modo de ser, este mesmo modo que se contrapõe a uma forma de (con)viver homogênea e intolerante. Enrique Dussel irá trabalhar com a ideia de conquista como um mecanismo necessário para assentar a colonização e a dominação do mundo descoberto, trata-se da imposição cultural do padrão de "Ser" e de relacionar-se no mundo. O autor menciona:

\footnotetext{
A "conquista" é um processo militar, prático, violento que inclui dialeticamente o Outro como o "si mesmo". O Outro, em sua distinção, é negado como Outro e sujeitado, subsumido, alienado a se incorporar à totalidade dominadora como coisa, como instrumento, como oprimido como "encomendado", como "assalariado" (nas futuras fazendas), ou como africano escravo (nos engenhos de açúcar ou outros produtos tropicais) ${ }^{13}$.
}

A etapa histórica de colonização e dependência gerou os filhos da invasão/opressão, importante categoria da sociologia política para compreensão da emergência das atuais características nas assembleias constitucionais populares e da refundação do Estado no continente.

Estes sujeitos historicamente oprimidos por um processo do qual atuaram como passivos e alijados de poder decisório irão compor um elemento chave na reinvenção do espaço público, como construção de um novo paradigma, plural e intercultural ${ }^{14}$. Ora, Dussel (1993) denomina esses sujeitos como um "bloco social de oprimidos", em que se pode, conforme a análise de José Carlos Moreira da Silva Filho, ${ }^{15}$ elaborar uma divisão entre um período pré-independência formal e outro a partir da formação dos Estados Nacionais periféricos. É o caso de exemplificar as vítimas do sistema, um por um, pela relevância na compreensão da busca do poder, direitos e espaço no novo constitucionalismo latino-americano.

O primeiro rosto da exclusão e opressão são os índios, violentados em sua cultura e sua forma de viver, escravizados e dizimados impiedosamente ${ }^{16}$, condenados pelo seu modo de ser e por sua (cosmo)visão de mundo, tido como povo atrasado e que mereceria o "sacrifício" imposto pelo "sábio europeu", por sua "modernidade" e sua "racionalidade superior" frente aos nativos embuídos de ignorância, infantilidade ou mesmo bestialidade.

O segundo rosto é o do negro escravo, ao qual Dussel atribui à seguinte referência,

Em Cartagena de Índias, o mesmo, podia acontecer numa colônia inglesa, portuguesa ou francesa, tirava-se a roupa dos africanos, homens e mulheres, e eram colocados em lugares visíveis, no mercado. Os compradores apalpavam seus corpos para constatar sua constituição, apalpavam seus órgãos sexuais para observar o Estado de saúde de mulheres e homens; observavam seus dentes para ver se estavam em boas condições, e, segundo seu tamanho, idade e força, pagavam em moedas de ouro o valor de suas pessoas, de suas vidas. Depois eram marcados com ferro em brasa. Nunca na história humana tal número e de tal maneira coisificados como mercadorias, foram tratados membros de nenhuma raça. Outra glória da Modernidade! ${ }^{17}$

de Frankfurt. Tradução de Jaime A. Classen. Petrópolis: Vozes, 1993.

13 DUSSEL, Enrique. 1492: o encobrimento do outro: a origem do mito da modernidade, conferências de Frankfurt. Tradução de Jaime A. Classen. Petrópolis: Vozes, 1993, p. 44.

14 Para analisar o Direito sob o viés do Pluralismo Jurídico, ver: WOLKMER, Antonio Carlos. Pluralismo jurídico: fundamentos de uma nova cultura do direito. 3. ed. São Paulo: Alfa Omega, 2001.

15 SILVA FILHO, José Carlos Moreira da. In: WOLKMER, Antonio Carlos. (Org.) Fundamentos de História do Direito. 4. ed. Rev. e Atual. Belo Horizonte: Del Rey, 2009.

16 Sobre violência contra os índios, ver importante obra do brasileiro Darcy Ribeiro, intitulada Povo Brasileiro, na primeira parte em que dirá o modo violento com que se deu a dominação na América indiana; ou ainda, vale mencionar José Carlos Moreira da Silva Filho (2009) em uma referência ao religioso espanhol Bartolomé de Las Casas: "Faziam apostas sobre quem, de um só golpe de espada, fenderia e abriria um homem pela metade, ou quem, mais habilmente e mais destramente, de um só golpe Ihe cortaria a cabeça, ou ainda sobre quem abriria melhor as entranhas de um homem de um só golpe. Arrancavam os filhos dos seios da mãe e lhes esfregavam a cabeça contra os rochedos enquanto os outros os lançavam à água dos córregos rindo e caçoando, e quando estavam na água gritavam: move-te, corpo de tal?! Outros, mais furiosos, passavam mães e filhos a fio da espada. (LAS CASAS apud SILVA FILHO, 2009, p. 279).

17 DUSSEL, Enrique. 1492: o encobrimento do outro: a origem do mito da modernidade, conferências de Frankfurt. Tradução de Jaime A. Classen. Petrópolis: Vozes, 1993, p.163. 
Torna-se importante mencionar, nesse ponto, conforme extraído da leitura Boaventura de Sousa Santos ${ }^{18}$, que após séculos de escravidão negra no Brasil, somente contemporaneamente é que se iniciou a resolução da dívida histórica com esse povo, sinal de que o processo histórico de colonização ainda produz efeitos práticos na racionalidade moderna (em crise),

Miren cómo Brasil, por primera vez en su historia, admite que es una sociedad racista y que necesita una acción afirmativa y de discriminación positiva, para las comunidades negras, afrodescendientes, casi doscientos años después de la independencia. Es decir que recién ahora los países están reconociendo su pasado colonial. ${ }^{19}$

Diante disso, passa-se para o terceiro rosto, representado pelo Mestiço, filhos de "Malinche" (a traidora) com o "espanhol dominador", ou mesmo, Iracema (traduzida na literatura brasileira SILVA FILHO, 2009), nem tanto sofrido como nas violências dos índios e negros, mas referencial simbólico do jugo europeu de "subcultura" latino-americana, colocado na situação de dependência da metrópole, ou seja, nega a cultura da mãe adotando a cultura do pai e é negado pela cultura do pai, por nascer com o sangue autóctone.

O quarto rosto, os Crioulos ou Criollos em espanhol, filhos de "brancos" nascidos nas índias, que segundo José Carlos Moreira da Silva Filho20, "[...] representaram uma classe dominada na Espanha, pelos Habsburgos e pelos Burbões e, no Brasil, pelos reis de Portugal." Ambos são os que, assim como os índios, têm sua terra natal a América, mas com uma confusão moral e histórica do seu passado e de sua cultura, sendo incorporados como submissos ao pujante processo civilizatório eurocêntrico. Com estes "rostos dusselianos", finalizam-se os quatro sujeitos representativos do período colonial.

Já ao tempo da formação do Estado nacional latino-americano, destacam-se mais três rostos que completam a revisão histórico-crítica dos atores dominados e produzidos como ausentes pelos poderes externos, desses o quinto é dos camponeses, constituídos por índios, negros e mestiços que sofreram opressão das oligarquias rurais proprietárias de terras e detentoras do poder, os quais foram, ao avançar do tempo, violentamente incorporados pelo sistema capitalista periférico de industrialização tardia. Há que se acrescentar ainda o chamado operariado urbano, sexto rosto da exploração e da opressão de que fala Dussel, segmento submisso ao capital internacional das empresas multinacionais ou transnacionais e das grandes burocracias financeiras.

Por fim, dentro do sistema peculiar do capitalismo, a "[...] existência de um 'exército operário de reserva' que o fraco capital periférico não pode absorver. Tal 'exército' compõe o sétimo rosto: o dos 'marginais' [...]."21 Esse último rosto é multifacetado, pois representa todas as categorias sociais de potenciais trabalhadores ou não, e que, devido às peculiaridades do sistema econômico altamente excludente, são postos à margem do sistema, assimilados de forma encobridora pela regulamentação jurídica, dentro de igualitarismo formalista resultante das promessas incumpridas da modernidade. ${ }^{22}$

Torna-se importante destacar a respeito duas conclusões de José Carlos Moreira da Silva Filho,

Emergindo dessa viagem às raízes do ser latino-americano, podem-se perceber duas coisas básicas: Primeiro, que este povo foi vítima de um processo de modernização que ocultou e oculta a violência praticada contra os seus pares, violência essa justificada por um discurso antropológico racista e cuja história é preciso ser resgatada para que se tenha noção da existência de um outro "sujeito histórico" que não o europeu; segundo que existe uma cultura sincrética popular, produto exclusivo das tradições latino-americanas e de sua interação com outras culturas, existe uma particularidade e especificidade que não se reduz às fórmulas das ideologias eurocentristas. ${ }^{23}$

18 SANTOS, Boaventura de Sousa. Pensar el Estado y la sociedad: desafíos actuales. Buenos Aires: Waldhuter, 2009.

19 SANTOS, Boaventura de Sousa. Pensar el Estado y la sociedad: desafíos actuales. Buenos Aires: Waldhuter, 2009, p. 28

20 SILVA FILHO, José Carlos Moreira da. In: WOLKMER, Antonio Carlos. (Org.) Fundamentos de História do Direito. 4. ed. Rev. e Atual. Belo Horizonte: Del Rey, 2009, p.301.

21 SILVA FILHO, José Carlos Moreira da. In: WOLKMER, Antonio Carlos. (Org.) Fundamentos de História do Direito. 4. ed. Rev. e Atual. Belo Horizonte: Del Rey, 2009, p 302.

22 SANTOS, Boaventura de Sousa. A Crítica da razão indolente: contra o desperdício de experiência. 8. ed. São Paulo: Cortez, 2011.

23 SILVA FILHO, José Carlos Moreira da. In: WOLKMER, Antonio Carlos. (Org.) Fundamentos de História 
Nesse sentido, como assinala Boaventura Santos, existe a produção de uma sociologia das ausências ${ }^{24}$, elaborada pela engenharia da modernidade e dos seus precursores, na qual fica evidente que, apesar do esforço prático e violento das classes dominantes, não impediu que no limiar da(s) crise(s) da modernidade ressurgisse a força cultural da identidade dos sujeitos historicamente negados e constituídos como seres subjugados, traduzidos em uma sociologia das emergências.

Contudo, para compreensão histórico-social dos movimentos políticos atuais nas novas constituintes, deve-se ter em conta a desmitificação do projeto epistemológico, inventado para dominar os sujeitos ausentes. Diante disso, o autor português menciona a importante categoria epistemológica: Sul Globa/25, necessária para fazer a leitura do mundo e da modernidade longe das concepções da "racionalidade ocidental europeizada" ou presentemente denominada de "norte americanizada". Entende-se como categoria epistêmica, já que a colonização é um processo não somente geográfico, mas compreende uma estratégia cognitiva de negação do outro.

As respostas para as questões intrincadas que a racionalidade positivista do direito tradicional apresenta não conseguem mais dar conta de esconder ou minimizar a emergência do debate e do acerto de contas com a história colonial.

Em razão disso, as reflexões sobre o Estado e o Direito no continente latino- americano encontram-se em avançado repensar, estão em marcha um paradigma de transição no direito (pelo viés de um pensamento jurídico $\mathrm{crítico}^{26}$ ) e no Estado (representado no Pluralismo Jurídico e na concepção de Estado Plurinacional ${ }^{27}$ ) que emerge a importância política de um movimento que vai em busca do resgate da cultura violentamente encoberta e marginalizada por um processo que se fez hegemônico e que ainda está sendo ocultado numa democracia manipulada.

Assim, entre outras questões, o que as recentes constituintes dos países como Bolívia, Equador e Venezuela expressam é a necessidade da reinvenção das instituições jurídicas e políticas na América Latina para inserção da cultura autóctone, negada ou ausente e, também da cultura sincrética popular produzida pelos rostos da exclusão social (resultado da colonização), para que estes possam emergir no contexto de manifestação de suas práticas políticas, fato inédito na história constitucional local.

\section{(RE)PENSAR É PRECISO: A REFUNDAÇÃO DO ESTADO E DO CONSTITUCIONALISMO NA AMÉRICA LATINA}

Diante desse resgate do Estado na América Latina, feito anteriormente, importa destacar o período de redemocratização e afirmação da hegemonia dos princípios do "Consenso de Washington", verdadeira carta político-econômico para as economias periféricas. As diretrizes de tal acordo irão impulsionar e aprofundar a política latino-americana dentro das ingerências neoliberais ou neocapitalistas ${ }^{28}$; paralelamente ao surgimento de constituições "avançadas", com aparatos e

do Direito. 4 ed. Rev. e Atual. Belo Horizonte: Del Rey, 2009, p. 302.

24 Ver do autor Boaventura de Sousa Santos o livro "A gramática do Tempo: para uma nova cultura política, capítulo 2 - Uma sociologia das ausências e uma sociologia das emergências", São Paulo: Cortez, 2006.

25 El primer paso es aprender con el Sur. El Sur son los pueblos, los países y las naciones que han sufrido más con el desarrollo del capitalismo global, porque se mantuvieron como países subdesarrollados, en desarrollo permanente, sin llegar nunca el marco de los países desarrollados. Y por eso, aprender con el Sur significa que la comprensión del mundo es mucha más amplia que la comprensión occidental del mundo. (SANTOS, 2009, p. 196)

26 Sobre o pensamento jurídico crítico na América Latina, ver a obra: WOLKMER, Antonio Carlos. Introdução ao pensamento jurídico crítico. 8. ed. São Paulo: Saraiva, 2012.

27 Observar texto publicado pelos autores na edição da Revista Pensar - Revista de Ciências Jurídica da Universidade de Fortaleza, número vol. 16, n² 2, 2011. "Tendências contemporâneas do constitucionalismo latino-americano: Estado plurinacional e pluralismo jurídico". Disponível em: <http://www. unifor.br/.>

28 "[...] Assim, proporíamos nominar esta experiência de neocapitalismo, pois parece-nos mais adequado aos seus contornos de projeto vinculado ao viés econômico do liberalismo, onde, ao que se vê, há uma intenção não expressa de liberar o capital - e o capitalismo financeiro - das amarras que acabaram por se constituir através, entre outros, dos conteúdos liberais dos núcleos moral e político-jurídico." 
garantias de direitos fundamentais, com pressupostos democráticos participativos, mas que não impuseram freios à ganância do capital transnacional. Tal dinâmica globalizada minorou os efeitos constitucionais democráticos das constituições, submeteu os Estados aos interesses dos grandes conglomerados e corporações, bem como estimulou a conivência dos poderes internos nacionais e a corrupção das estruturas de dominação.

Comprova a primeira hipótese a questão da privatização da saúde, retratada no exemplo do Chile, bem como no assédio aos direitos trabalhistas no Brasil, no colapso financeiro da Argentina e na guerra da água e do gás na Bolívia, processos que podem ser caracterizados como modelos de (neo)colonialismo, desencadeados durante a última década do século passado e no início deste.

Nesse cenário institucionalizado do Estado periférico, importa resgatar a assertiva proposta por A. C. Wolkmer ${ }^{29}$, em que a presença do ente político em um contexto como o do continente é fundamental, senão, veja-se que:

\begin{abstract}
Uma concepção crítica do Estado periférico latino-americano passa pelo resgate da autenticidade e originalidade de sua identidade cultural. Em suma, a presença do Estado na América Latina, não é só necessária como até inevitável, entretanto, não mais como criador e tutor autoritário da Sociedade Civil, mas como articulador e reordenador dos espaços democráticos de acesso popular, como autêntico mandatário da Sociedade Civil, plenamente organizada e pela participação da cidadania popular. ${ }^{30}$
\end{abstract}

Antes de adentrar ao tema da refundação do Estado, assinala-se a presença das crises, pois é, em um cenário de superação desta que irá emergir o movimento pluralista por outro Direito e outro Estado, de base popular democrática participativa ou mesmo materialmente igualitária, como irão introduzir alguns autores que serão vistos adiante, no direcionamento de uma democracia de alta intensidade. ${ }^{31}$

Nessa perspectiva, as chamadas crises do Estado (conceitual, estrutural, institucional/ constitucional, funcional e política) ${ }^{32}$ representam o esgotamento dos modelos a serviço dos interesses dos poderes hegemônicos; os próprios princípios políticos e epistemológicos esvaíram-se e, por consequência, exauriram o embasamento sólido de uma concepção de Estado interventor, como bem aponta José Luis Bolzan de Morais,

Assim, o fundamento filosófico do modelo fragmentou-se, o que implicou o solapamento de suas bases e produziu fissuras que necessitam de um projeto de reconstrução que vá além de fórmulas matemáticas de compatibilização de recursos, e que ultrapasse os limites de uma sociedade individualista-liberal, constituída a de uma mônada isolada, cujos compromissos não ultrapassam as fronteiras de seu universo individual, o que, com certeza, pressuporia a refundação de seus fundamentos mesmos. ${ }^{33}$

Dessa maneira, a própria ideia de refundação parte da reconstrução da constituição institucional e política do Estado, em que,

Deve-se ter claro que a Constituição como documento jurídico-político, sempre esteve submersa em um jogo de tensões e poderes, o que não pode significar, como querem alguns, a sua transformação em programa de governo, fragilizando-a como paradigma ético-jurídico da sociedade e do poder $[\ldots]^{34}$

É justamente com a reinvenção do paradigma de democracia, a qual deve ser resgatada aos interesses das camadas populares, que se insurgem os movimentos sociais na exigência de tomada

(MORAIS, 2002, p. 17).

29 WOLKMER, Antonio C. Elementos para uma Crítica do Estado. Porto Alegre: Sérgio Fabris, 1990.

30 WOLKMER, Antonio C. Elementos para uma Crítica do Estado. Porto Alegre: Sérgio Fabris, 1990, p. 43.

31 SANTOS, Boaventura de Sousa. (Org.). Democratizar a democracia: os caminhos da democracia participativa. $3^{\circ} \mathrm{Ed}$. Rio de Janeiro: Civilização Brasileira, 2005, p. 39.

32 Para explorar tais crises ver José Luis Bolzan de Morais, As Crises do Estado e da Constituição e a transformação espacial dos Direitos Humanos, Porto Alegre: Livraria do Advogado, 2002. Igualmente: Adauto Novaes (Org.). A Crise do Estado-Nação. Civilização Brasileira: Rio de Janeiro, 2003.

33 MORAIS, Jose Luis Bolzan de. Crises do Estado e da constituição e a transformação espacial dos direitos humanos. Porto Alegre: Livraria do Advogado, 2002, p. 44.

34 MORAIS, Jose Luis Bolzan de. Crises do Estado e da constituição e a transformação espacial dos direitos humanos. Porto Alegre: Livraria do Advogado, 2002, p. 47. 
de decisões políticas que irão influir em seu próprio futuro, tendo em vista que do seu passado foram apenas agentes passivos. Pode-se notar a importância de tal fundamento nas novas constituições, afirmada em teorias mais recentes:

Desde este punto de vista, el nuevo constitucionalismo reivindica el carácter revolucionario del constitucionalismo democrático, dotándolo de los mecanismos actuales que pueden hacerlo más útil en la emancipación y avance de los pueblos a través de la constitución como mandato directo del poder constitutuyente y, en consecuencia, fundamento último de la razón de ser del poder constituido. Por todo ello, el nuevo constitucionalismo busca analizar, en un primer momento, la exterioridad de la constitución; es decir, su legitimidad, que por su propia naturaleza sólo pueda ser extrajurídica. ${ }^{35}$

Diante disso, a incerteza dos resultados no processo do "constitucionalismo transformador"36 ainda é um risco que se deve correr, pois jamais se pode prever quais as consequências, sendo descabido aos estudiosos intentar tal tarefa. Entretanto se aposta na capacidade de mudança, em rever as questões mal resolvidas de um passado de hegemonia de poucos, concentrando riquezas em cima do trabalho e do sofrimento de muitos. O que se pode afirmar é a inauguração de um processo de negação, mas negação de uma hegemonia conservadora da desordem social e política, em contraposição ao histórico de negação de sujeitos e culturas.

Em razão disso, Boaventura S. Santos ${ }^{37}$ lança a ideia do "Estado Experimental" como uma nova institucionalidade para superação das crises funcionais e de institucionalidade, uma reinvenção deste aparato moderno, para atender às demandas por mudança da sociedade atual, calcada em diferentes formas de democracia. Sobre este aspecto, a própria função do Estado como regulador ou gestor do bem-estar deixa de ser unilateral e passa a ser compartida, um projeto para além da democracia representativa, pautado na "fiscalidade participativa." ${ }^{38}$.

Ora, ainda na sequência as palavras do sociólogo de Coimbra quanto a este recente modelo de institucionalidade,

Esta nova forma de um possível Estado democrático deve assentar em dois princípios de experimentação política. O primeiro é que o Estado só é genuinamente experimental na medida em que as diferentes soluções institucionais multiculturais são dadas iguais condições para se desenvolverem segundo a sua lógica própria. Ou seja, o Estado experimental é democrático na medida em que confere igualdade de oportunidades às diferentes propostas de institucionalidade democrática. ${ }^{39}$

E prossegue,

Nestas circunstâncias, o Estado experimental deve, não só garantir a igualdade de oportunidades aos diferentes projectos de institucionalidade democrática, mas deve também - e é este o segundo princípio de experimentação política - garantir padrões mínimos de inclusão, que tornem possível a cidadania activa necessária a monitorar, acompanhar e avaliar o desempenho dos projectos alternativos. Estes padrões mínimos de inclusão são indispensáveis para transformar a instabilidade institucional em campo de deliberação democrática. O novo Estado de bem-estar é um Estado experimental e é a experimentação contínua com participação activa dos cidadãos que garante a sustentabilidade do bem-estar. ${ }^{40}$

A temática da refundação do Estado é um assunto em transição, explica-se: o Estado moderno tem seu colapso, e suas crises já não conseguem ser superadas por velhos métodos "salvacionistas", pois a falência é epistemológica e prática. A perversidade do sistema econômico extraiu aquilo que

35 MARTÍNEZ DALMAU, Rubén. VICIANO PASTOR, Roberto. Fundamento teórico del nuevo constitucionalismo latinoamericano. In: VICIANO PASTOR, Roberto. (Editor) Estudios sobre el nuevo Constitucionalismo Latinoamericano. Valencia: Tirant lo Blanch, 2012, p. 20.

36 SANTOS, Boaventura de Sousa. Refundación del Estado en América Latina: perspectivas desde una epistemología del Sur. Lima: Instituto Internacional de Derecho y Sociedad, 2010, p. 71.

37 SANTOS, Boaventura de Sousa. Refundación del Estado en América Latina: perspectivas desde una epistemología del Sur. Lima: Instituto Internacional de Derecho y Sociedad, 2010, p. 110

38 SANTOS, Boaventura de Sousa. A Gramática do Tempo: para uma nova cultura política. São Paulo: Cortez, 2006, p. 373.

39 SANTOS, Boaventura de Sousa. A Gramática do Tempo: para uma nova cultura política. São Paulo: Cortez, 2006, p. 375.

40 SANTOS, Boaventura de Sousa. A Gramática do Tempo: para uma nova cultura política. São Paulo: Cortez, 2006, p. 375. 
Ihe convinha do presente modelo, fixou as funções e aparelhou o sistema político pelo viés financeiro capitalista globalizado. Ou seja, a única saída que resta para as maiorias historicamente alijadas dos poderes políticos, conforme visto acima, é a refundação de outro modelo de Estado, um ente político de natureza popular (assembleia constituinte de caráter popular).

Dessa maneira, a ideia que Boaventura S. Santos lança é absorvida e se encontra no esgotamento de um modelo de racionalidade histórica, inventada para um contexto e um espaço geográfico (América Latina). Este modelo dominador, no limiar do século XXI, encontrou seus limites, e os precursores destes não obtêm artifícios para manter o domínio da situação como o fizeram em tempos passados, apesar de intentá-los (vejam-se os exemplos de neocolonialismo mencionados acima).

Além da mudança paradigmática do modelo de Estado baseado na racionalidade centralizadora eurocêntrica, vale destacar um movimento constitucional de novo tipo, tratada pelo autor português como uso contra-hegemônico de instrumentos dominantes (2010). É a referência ao uso do constitucionalismo, instrumento historicamente liberal, arma de defesa da burguesia emergente contra o Estado absolutista nas revoluções iluministas,

Entiendo por instrumentos hegemónicos las instituciones desarrolladas en Europa a partir del siglo XVIII por la teoría política liberal con vista a garantizar la legitimidad y gobernabilidad del Estado de Derecho moderno en las sociedades capitalistas emergentes. Se trata de instrumentos hegemónicos porque fueron diseñados para garantizar la reproducción ampliada de las sociedades capitalistas de clases y porque son creíbles como garantes de la consecución del bien común, incluso por parte de las clases populares en sí afectadas negativamente por ellos. ${ }^{41}$

E destaca, mencionando a contra-hegemonia:

El uso contrahegemónico, como el nombre lo indica, significa la apropiación creativa por parte de las clases populares para sí de esos instrumentos a fin de hacer avanzar sus agendas políticas más allá del marco político-económico del Estado liberal y de la economía capitalista. ${ }^{42}$

Destarte, em termos de uma visão de descolonialidade, esse instrumento utilizado pela lógica liberal passa a servir de passagem para outro modo de pensamento político constitucional, caracterizado por diversas concepções democráticas, como pluralismo jurídico, interculturalidade e plurinacionalidade. Por conseguinte, uma nova institucionalidade baseada no respeito à diferença $\mathrm{e}$ na desconstrução de desigualdades históricas, atribuindo poder democrático popular às comunidades segregadas pelo poder opressor das elites dominantes, oligarquias e aristocracias proprietárias comprometidas com o poder externo discriminador.

Afinal, pode-se caracterizar que este novo constitucionalismo de tipo plural e intercultural traduz um movimento popular de exigibilidade de uma nova "mirada política", com mudanças institucionais profundas, um constitucionalismo que vem das bases e é por esta influenciado, um "constitucionalismo desde abajo"; no qual o poder constituinte popular se sobrepõe ao poder constituído, estando comprometido com os estratos sociais e econômicos dominantes (constituinte "desde arriba"). Compõem-se numa manifestação política popular, participativa e atuante de diversos setores, alguns historicamente marginalizados e isolados por um pensamento e prática políticojurídica eurocêntrica.

Nessa senda, atenta-se que a característica peculiar para este período é a mudança no paradigma da ordem jurídica, que agora passa a compreender normatividades plurais, baseado nas diferenças e no diálogo intercultural, equidistante das correlações burocráticas de poder e de concentração das decisões nas mãos de uns poucos. Certamente, não é mais uma ordem constitucional liberal do Estado racional moderno, pois projeta outro momento do Estado e do próprio constitucionalismo ocidental. O que se está assistindo presentemente no continente latino-americano não é ao fim de um modelo histórico político-jurídico, mas aos primeiros indícios de um novo período institucional, ainda em fase de transição paradigmática.

Certamente, o sujeito latino-americano foi incluído em um projeto racionalizante de modernidade, em que o papel foi predefinido na chegada dos colonizadores brancos, os agentes

41 SANTOS, Boaventura de Sousa. Refundación del Estado en América Latina: perspectivas desde una epistemología del Sur. Lima: Instituto Internacional de Derecho y Sociedad, 2010, p. 59.

42 SANTOS, Boaventura de Sousa. Refundación del Estado en América Latina: perspectivas desde una epistemología del Sur. Lima: Instituto Internacional de Derecho y Sociedad, 2010, p. 59. 
"superiores" da civilização, ou seja, os inventores da forma de ser e viver que determinaram a condição do outro representante da "barbárie", do nativo que deve ser excluído e negado como ser inferior e marginal.

Em suma, a marginalidade e a exclusão segregadora das populações latino-americanas, na presente crise da totalidade moderna, acabam por permitir uma tomada de consciência da sua própria condição de dependência, favorecendo a criação de processos emancipadores capazes de romper com os sistemas e as instituições de dominação colonial que os produziu como sujeitos ausentes de sua própria história. Tais assertivas de propostas político-institucionais vão de encontro às tendências mais recentes do novo constitucionalismo na América Latina, onde a questão central presentemente passa pela refundação do espaço político, pela introdução de um paradigma do Estado Pluricultural.

\section{CONSIDERAÇÕES FINAIS}

Constatou-se, assim, diante do resgate histórico-crítico da formação do Estado e do Direito em Nuestra América, que importa refletir a partir de uma ideia bastante latente atualmente nos espaços de discussão político-jurídico no continente, tal se trata da refundação do Estado (Estado Plurinacional) e do Direito (Pluralismo Jurídico) como perspectiva de transformação e mudança de paradigmas. Essas circunstâncias inauguradas nas recentes constituintes insurgentes nos países andinos revelam a iminência do debate político-jurídico por processos liberadores.

Diante disso, buscou-se trabalhar como foi elaborado o processo sócio-político das ausências populares na construção do poder nestes Estados periféricos da realidade latino-americana, resgatando algumas categorias de sujeitos sociais marginalizados ou mesmo excluídos da horda decisória político-institucional fetichizada ${ }^{43}$ da tradição republicana burguesa expressa na democracia representativa. Intentou-se apresentar por que as atuais constituições populares e os novos paradigmas de transição no Direito (comunitarismo e igualitarismo judicial) e no Estado (plurinacionalidade e "buen vivir") devem estar na ordem do dia do debate (jurídico-político) teórico crítico latino-americano.

A presente reconstrução histórica na primeira e na segunda etapa do estudo evidenciou quem são os sujeitos históricos ausentes e como se deu sua inserção jurídico-político nas esferas decisórias. Essa categoria é uma fonte destacada de análise, na medida em que uma rápida incursão no novo constitucionalismo latino-americano corrobora a existência destes atores nos movimentos que eclodiram a exigibilidade por uma assembleia constituinte popular de transformação dos poderes políticos e da legitimação de novos arranjos institucionalizados.

Certamente, no processo de formação de nossas instituições jurídicas e políticas, atravessadas por exclusões e desigualdades sociais, destacou-se a contraditória confluência, de um lado, da herança colonial ibérica burocrática-patrimonialista, marcada por práticas ausentes de democracia autêntica e participação popular; de outro, de uma tradição liberal-individualista que serviu e sempre foi utilizada, não em função autêntica da sociedade em geral, mas no interesse exclusivo de grande parcela das elites hegemônicas locais, detentoras do poder, da propriedade privada e dos meios de produção da riqueza.

Resta nada mais que observar as respostas políticas e jurídicas que os sujeitos ausentes vêm dando às manifestações sociais produzidas por rupturas, apesar do ceticismo político dos setores conservadores, que prosseguem insistindo na matriz de fundamentação eurocêntrica, assentada em respostas elaboradas ou pré-programadas, explícita reação ao momento político de esgotamento. Tem-se presente a necessidade de repensar as formas hegemônicas de Estado (em crise), os modelos políticos tradicionais e as formas jurídicas dominantes; o que traduz a imperiosidade de um momento de catalisar as lógicas histórico-críticas descolonizadoras.

Em suma, emerge neste processo de transição, marcado pela forte demanda por um pensamento crítico-construtivo na esfera da Política e do Direito, a refundação de horizontes insurgentes, plurais, interculturais e liberadores, nascidos das práticas sociais no interior das nações latino-americanas.

43 Sobre "Fetichização do poder", ver: DUSSEL, Enrique. 20 Teses de Política. 1. ed. Buenos Aires: Consejo Latinoamericano de Ciencias Sociales - CLACSO; São Paulo: Expressão Popular, 2007. 
ACOSTA, Alberto e otros. Plurinacionalidad - Democracia en la Diversidad.Quito: Ediciones Abya Yala, 2009.

CARVALHO, José Murilo de. A Construção da Ordem: a elite política imperial. Rio de Janeiro: Campus, 1980.

CHATELET, François; PISIER-KOUCHNER, Évelyne. As Concepções Políticas do Século XX. História do pensamento político. Rio de Janeiro: Zahar, 1983.

CONSTITUCIóN de la República del Ecuador. Asamblea Nacional. Comisión Legislativa y de Fiscalización. Quito, 2008.

CORTE CONSTITUCIONAL DEL ECUADOR PARA EL PERÍODO DE TRANSICIÓN. EI Nuevo Constitucionalismo en América Latina. Quito: Corte constitucional, 2010.

CONSTITUCIóN Politica del Estado. Gaceta Oficial de Bolivia. Edición Oficial. La Paz, Bolívia, Febrero de 2009.

CRUZ COSTA, João. Contribuição à história das ideias no Brasil. Rio de Janeiro: José Olympio, 1956.

DE LA TORRE RANGEL, Jesus Antonio. Sociología Jurídica y Uso Alternativo del Derecho. Mexico: Instituto Cultural de Aguascalientes, 1997.

De MARZO, Giuseppe. Buen Vivir - Para una Democracia de la tierra. La Paz: Plural Editores, 2010.

DUSSEL, Enrique. 20 Teses de Política. 1. ed. Buenos Aires: Consejo Latinoamericano de Ciencias Sociales - CLACSO; São Paulo: Expressão Popular , 2007.

1492: o encobrimento do outro: a origem do mito da modernidade, conferências de Frankfurt. Tradução de Jaime A. Classen. Petrópolis: Vozes, 1993.

ESPINOSA GALLEGOS-ANDA, Carlos; CAICEDO TAPIA, Danilo (Eds.). Derechos Ancestrales: Justicia en contextos Plurinacionales. Quito: Ministerio de Justicia y Derechos Humanos, 2009.

GUtierReZ, Gustavo. A Força Histórica dos Pobres. 2. ed. Petrópolis: Vozes, 1984.

IANNI, Octavio. A Formação do Estado Populista na América Latina. 2. ed. São Paulo: Ática, 1989.

LECHNER, Norbert (Ed.). Estado y Política en América Latina. Mexico: Siglo Vientiuno, 1981.

KAPLAN, Marcos. Formación del Estado Nacional en América Latina. Buenos Aires: Amorrortu, 1983.

MARTÍNEZ DALMAU, Rubén. VICIANO PASTOR, Roberto. Fundamento teórico del nuevo constitucionalismo latinoamericano. In: VICIANO PASTOR, Roberto. (Editor) Estudios sobre el nuevo Constitucionalismo Latinoamericano. Valencia: Tirant lo Blanch, 2012.

MARTNER, Gonzalo (Coord.). "El Estado en América Latina". América Latina hacia el 2000. Caracas: Editorial Nueva Sociedad/UNITAR, 1985.

MORAIS, Jose Luis Bolzan de. Crises do Estado e da constituição e a transformação espacial dos direitos humanos. Porto Alegre: Livraria do Advogado, 2002.

NEDER, Gizlene. Iluminismo Jurídico-penal Luso-brasileiro. Obediência e submissão. Rio de Janeiro: Freitas Bastos, 2000.

NOGueira feRnANDEZ, Albert. Constitución. Plurinacionalidad y Pluralismo Jurídico en Bolivia. La Paz: Oxfam Gran Bretaña, 2008.

NOGARE, Pedro Dalle. Humanismos e Anti-humanismos. Introdução à Antropologia Filosófica. 10. ed. Petrópolis: Vozes, 1985.

NOVAES, Adauto (Org.). A Crise do Estado-Nação. Civilização Brasileira: Rio de Janeiro, 2003. 
PINHEIRO, Paulo Sérgio (Coord.). O Estado na América Latina. Rio de Janeiro: Paz e Terra; São Paulo: CEDEC, 1977.

PIRES, Cecília M. Pinto. Reflexões sobre Filosofia Política. Santa Maria: Pallotti, 1986.

RUBINSTEIN, Juan Carlos (Comp.). El Estado Periferico Latinoamericano. Buenos Aires: EUDEBA, 1988.

SANTOS, Boaventura de Sousa. A Gramática do Tempo: para uma nova cultura política. São Paulo: Cortez, 2006.

(Org.). Democratizar a democracia: os caminhos da democracia participativa. 3. ed. Rio de Janeiro: Civilização Brasileira, 2005.

2011.

A Crítica da razão indolente: contra o desperdício de experiência. 8. ed. São Paulo: Cortez,

Pensar el Estado y la sociedad: desafíos actuales. Buenos Aires: Waldhuter, 2009.

Refundación del Estado en América Latina: perspectivas desde una epistemología del Sur. Lima: Instituto Internacional de Derecho y Sociedad, 2010.

SILVA FILHO, José Carlos Moreira da. In: WOLKMER, Antonio Carlos. (Org.) Fundamentos de História do Direito. 4. ed. Rev. e Atual. Belo Horizonte: Del Rey, 2009.

SOTELLO, Ignacio. Sociologia da América Latina. Rio de Janeiro: Pallas, 1975.

WEHLING, Arno; __ Maria José C. M. Formação do Brasil Colonial. Rio de Janeiro: Nova Fronteira, 1999.

WIARDA, Howard J. O Modelo Corporativo na América Latina e a Latino-americanização dos Estados Unidos. Petrópolis: Vozes, 1983.

WOLKMER, Antonio C. Elementos para uma Crítica do Estado. Porto Alegre: Sérgio Fabris, 1990.

O Terceiro Mundo e a Nova Ordem Internacional. 2. ed. São Paulo: Ática, 1994.

2001.

Pluralismo jurídico: fundamentos de uma nova cultura do direito. 3. ed. São Paulo: Alfa Omega,

Introdução ao pensamento jurídico crítico. 8. ed. São Paulo: Saraiva, 2012.

História do Direito no Brasil. 3. ed. Rio de Janeiro: Forense, 2002.

Humanismo e Cultura Jurídica no Brasil. Florianópolis: Fundação Boiteux, 2004.

FAGUNDES, Lucas Machado. Tendências Contemporâneas do Constitucionalismo Latino-americano: Estado plurinacional e pluralismo jurídico. Pensar. Revista de Ciências Jurídicas. Fortaleza: Unifor. V.16, no 02, jul./dez. 2011. p. 371-408.

YRIGOYEN FAJARDO, Raquel Z. (Ed.). Pueblos Indígenas: Constituciones y REformas Políticas en América Latina. Bogota: ILSA; Brasília: INESC; IIDS: Lima, 2010. 